\title{
Pemanfaatan Model Jigsaw Pada Game Edukasi Sebagai Media Pembelajaran Untuk Anak Penderita Tunawicara
}

\author{
Zulkifli $^{1}$, Santi Nurul Fianti ${ }^{2}$, Azrai Sirait \\ ${ }^{1}$ STIA Setih Setio, Muara Bungo, Indonesia \\ ${ }^{2}$ STAIN Bengkalis, Bengkalis, Indonesia \\ ${ }^{3}$ Universitas Asahan, Kisaran, Indonesia
}

\section{Info Artikel \\ Article history: \\ Received: 21122018 \\ Revised: 13012019 \\ Accepted: 28012019}

\section{Kata Kunci:}

Jigsaw

Game Edukasi

Media Pembelajaran

Tunawicara

Waterfall

\section{Penulis Korespondensi: Zulkifli \\ z.skom@yahoo.com}

\begin{abstract}
An Educational game are learning media that are educational so that users get the benefit of increasing knowledge by playing while learning. The use of educational games by applying jigsaw or group learning can make it easier for students to absorb lessons because in educational games already presented learning materials for recognizing letters and reading which are equipped with audio visuals. The educational game presents lesson material to recognize letters and read sentences which are equipped with text, images and letters that can be seen clearly and are equipped with the sound of letters and sentences. By using this educational game, it can help students in the process of recognizing letters and reading more so that they can increase students' knowledge
\end{abstract}

\begin{abstract}
Abstrak
Isi Game edukasi merupakan media pembelajaran yang bersifat mendidik agar pengguna mendapatkan manfaat yaitu menambah pengetahuan dengan cara bermain sambil belajar. Pemanfaatan game edukasi dengan menerapakan pembelajaran jigsaw atau berkelompok dapat memudahkan siswa-siswi dalam menyerap pelajaran karena di dalam game edukasi sudah disajikan materi-materi pelajaran mengenal huruf dan membaca yang dilengkapi dengan audio visual. Game edukasi menyajikan materi pelajaran mengenal huruf dan membaca kalimat yang dilengkapi dengan tampilan teks, gambar dan huruf yang dapat dilihat dengan jelas serta dilengkapi dengan bunyi suara huruf dan kalimat. Dengan menggunakan game edukasi ini dapat membantu anak didik dalam proses mengenal huruf dan membaca lebih meningkat sehingga dapat menambah pengetahuan anak didik
\end{abstract}

\section{PENDAHULUAN}

Tunawicara adalah suatu kelainan baik dalam pengucapan (artikulasi) bahasa maupun suara dari bicara normal, sehingga menimbulkan kesulitan dalam berkomunikasi lisan dalam lingkungan. Tuna wicara dapat disebabkan karena gangguan pada saraf, seperti pada cerebral palsy, dan terutama karena gangguan pendengaran, baik sejak lahir (congenital) atau didapat kemudian (acquired) [1]. Dalam keadaan tuna wicara, otot bibir tidak digunakan selayaknya orang normal. Hal ini menyebabkan otot-otot bibir cenderung mengalami atrofi. Atrofi otot yaitu keadaaan otot mengecil sehingga kehilangan kemampuan untuk kontraksi, yang umumnya disebabkan tidak digunakan secara cukup atau penyakit [2],[3]. Otot bibir memiliki serabut otot yang bersifat elastis, mempunyai dua macam tonus yaitu aktif dan pasif. Pada waktu kontraksi terdapat tonus yang aktif dan apabila dalam keadaan dilatasi terdapat tonus pasif.

Anak tuna wicara mendapatkan terapi wicara untuk mengaktivasi kinerja otot-otot bibir sehingga dapat memperbaiki aktivitas otot dan dapat membantu memperbaiki kualitas pengucapan. Terapi wicara dilakukan minimal seminggu 2 kali dengan durasi tiap terapi selama kurang lebih 1-2 jam. Terapi wicara dilakukan tergantung dari penyebab dan keluhan wicara seperti artikulasi, irama bicara, kekuatan, ketepatan, dan kecepatan bicara. Dalam melatih otot bibir pada terapi wicara dapat dilakukan secara mandiri atau tanpa bantuan alat dan dengan bantuan alat. Terapi kekuatan otot bibir tanpa menggunakan alat dilakukan dengan latihan membuka dan menutup mulut, menutup mulut dan menggerakkan bibir ke kanan dan ke kiri, mengisi 
udara pada mulut dan posisi bibir mengatup kemudian kedua pipi kanan dan kiri ditekan sampai udara keluar. Gerakan ini menggunakan irama senam untuk memudahkan anak mengingat dan mengulangi gerakan latihan. Selain itu juga dilakukan teknik pemijatan dengan gerakan kedua jari telunjuk memijat bibir atas kearah samping, bibir bawah, dan kemudian bersama-sama bibir atas dan bawah [4].

Penelitian telah dilakukan Suryani. Berdasarkan hasil penelitian dapat disimpulkan bahwa penggunaan metode kooperatif tipe jigsaw dapat meningkatkan prestasi belajar menentukan KPK dan FPB siswa kelas IV A SD Negeri Pajambon Kabupaten Kuningan. Hal ini dapat dilihat dari hasil tes evaluasi siklus I pertemuan 1 memperoleh rata-rata kelas sebesar 59,5 dengan prosentase ketuntasan sebesar 25\%. Hasil penelitian siklus I pertemuan 2 memperoleh rata-rata kelas sebesar 66 dan prosentase ketuntasan sebesar 40\%. Sedangkan hasil penelitian pada Siklus II pertemuan 1, diperoleh rata-rata kelas sebesar 71 dengan prosentase ketuntasan sebesar 50\%, siklus II pertemuan 2 diperoleh rata-rata kelas sebesar 84 dengan prosentase ketuntasan sebesar $85 \%$. Berdasarkan pembahasan setiap siklus, maka secara keseluruhan telah terjadi peningkatan hasil belajar dari silklus 1 pertemuan 1 baik pada nilia rata-rata kelas maupun persentasi ketuntasan, dimana penelitian mencapai kriteria keberhasilan saat baik nilai rata-rata kelas maupuan prosentasi ketuntasan mencapai kriteria keberhasilan, 70 dan $80 \%$, yaitu pada siklus II pertemuan 2 sebesar 84 untuk rata-rata kelas dan $85 \%$ untuk prosentase penilaian [5].

\section{METODE PENELITIAN}

Pada penelitian ini penulis menggunakan metode SDLC Waterfall. Waterfall atau Classic Life Cycle merupakan metode yang banyak digunakan pada Software Enginering, metode ini melakukan pendekatan secara sistematis dan terurut dari level kebutuhan sistem lalu menuju ke tahap analisis, desain, implementasi, dan pengujian sistem. Disebut Waterfall karena tahap demi tahap yang dilalui harus menunggu selesainya tahap sebelumnya dan berjalan berurutan. Adapun tahapan-tahapan pada penelitian ini adalah:

a. Pengumpulan Data. Tahapan ini dilakukan untuk memperoleh data yang diperlukan yaitu melakukan observasi ke kelas untuk mengidentifikasi peserta didik dilakukan pengelompokan dengan memilih peserta didik yang kategori pintar, sedang dan kurang pintar.

b. Analisis. Tahapan analisis dilakukan untuk menganalisis permasalahan dan menentukan kebutuhan yang diperlukan dalam pembuatan sistem. Hasil analisis tersebut kemudian dijadikan dasar dalam membuat perancangan desain sistem.

c. Desain. Tahapan desain dilakukan untuk mengetahui alur data dan proses yang terjadi sistem. Perancangan desain sistem dilakukan menggunakan Unified Modeling Language (UML).

d. Implementasi Sistem. Tahapan implementasi dilakukan untuk menerjemahkan desain yang telah dibuat menggunakan bahasa pemrograman agar dapat dikembangkan menjadi sebuah sistem atau perangkat lunak. Sistem akan dibuat dan dikembangkan berbasis desktop menggunakan visual basic untuk melakukan pengujian penggunaan aplikasi pembelajaran dalam menerapkan metode jigsaw kedalam system komputerisasi.

e. Pengujian Sistem. Tahapan pengujian sistem dilakukan untuk mengetahui apakah sistem yang dibuat telah sesuai dengan tujuan yang direncanakan. Pengujian sistem dilakukan menggunakan metode blackbox testing.

f. Berikut merupakan gambar ilustrasi dari metode penelitian yang dilakukan:

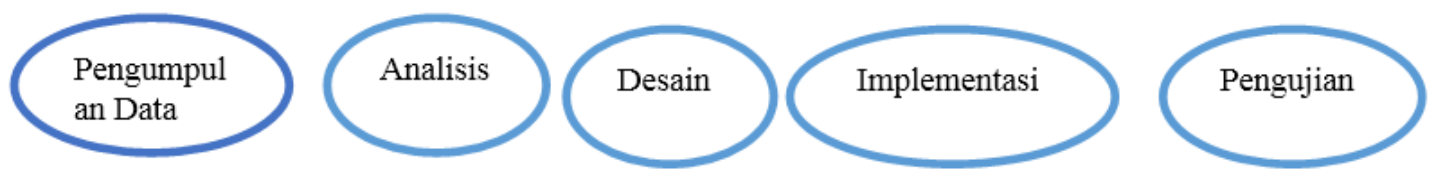

Gambar 1. Metode Penelitian

\section{DISKUSI DAN HASIL}

3.1 Pengumpulan data

Tahapan pengumpulan data dilakukan dengan cara mengumpulkan data-data siswa-siswi, data siswa-siswi dimulai dari data siswa-siswi kelas 1 SDLB Kisaran. Pengumpulan data-data siswa dari kelas ini dilakukan dengan cara mendatangi langsung SDLB Kota Kisaran. Data-data yang dikumpulkan antara lain :

a. Data siswa-siswi kelas 1

b. Nama dan Jumlah siswa yang tingkat kecerdasannya tinggi

c. Nama dan jumlah siswa-siswi yang tingkat kecerdasannya dibawah rata-rata. 
Tabel 1. Data Hasil Pendataan Murid Kategori Pintar

\begin{tabular}{llllll}
\hline No & Nama Siswa-siswi & Kelas & JK & Usia & Keterangan murid \\
\hline 1. & Saputra Bugis & 1 SDLB & L & 6 tahun & Pintar \\
2. & Marria nainggolan & 1 SDLB & P & 6 tahun & Pintar \\
3. & Heriyansah siregar & 1 SDLB & L & 6 tahun & Pintar \\
4. & Zaki simatupang & 1 SDLB & L & 6 tahun & Pintar \\
\hline
\end{tabular}

Tabel 2. Data Hasil Pendataan Murid Kategori Kurang Pintar

\begin{tabular}{cccccc}
\hline No & Nama Siswa-siswi & Kelas & JK & Usia & Keterangan murid \\
\hline 1. & Dedi saputra & 1 SDLB & L & 6 tahun & Kurang pintar \\
2. & Heru danis & 1 SDLB & L & 6 tahun & Kurang pintar \\
3. & Fizay satria & 1 SDLB & L & 6 tahun & Kurang pintar \\
4. & Hendrik & 1 SDLB & L & 6 tahun & Kurang pintar \\
5. & Reza faiza & 1 SDLB & P & 6 tahun & Kurang pintar \\
6. & Sari dewi putri & 1 SDLB & P & 6 tahun & Kurang pintar \\
7 & Karlota mutia & 1 SDLB & P & 6 Tahun & Kurang pintar \\
8 & Weni desi & 1 SDLB & Kurang pintar \\
\hline
\end{tabular}

\subsection{Analisis dan Desain Sistem}

Untuk menjelaskan alur dan konsep dari penelitian, penulisan menggunakan Unified Modeling Language (UML) untuk memodelkan alur penelitian yang dilakukan. UML digambarkan mulai dari use case dan activity diagram. UML dari system media pembelajaran dapat dilihat pada gambar.

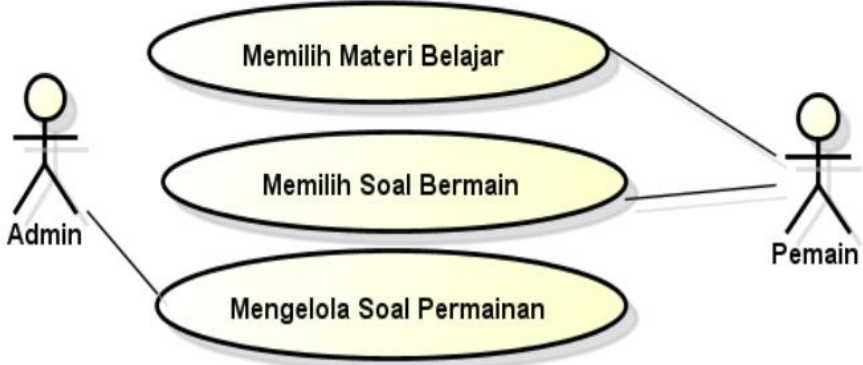

Gambar 2. Use Case Login Admin

Pada Gambar 2 use case aplikasi dapat dilihat bagaimana hubungan penggunaan aplikasi antara admin dan user. Actor admin disini adalah wali kelas masing-masing kelas dan Actor user adalah siswa-siswi atau disebut pemain sebagai pengguna.

a.Mendefinisikan Use Case

Sebuah use case harus mendeskripsikan sebuah pekerjaan di mana pekerjaan akan memberikan informasi yang bermanfaat bagi aktor.

Tabel 3. Mendefinisi Use Case

\begin{tabular}{lll}
\hline No & \multicolumn{1}{c}{ Use Case } & \multicolumn{1}{c}{ Deskripsi } \\
\hline 1 & Memilih Materi Belajar & $\begin{array}{l}\text { Use Case memilih materi belajar merupakan proses memilih materi } \\
\text { pembelajaran, melihat isi materi dan mendengarkan suara pengucapan } \\
\text { penjelasan dari setiap materi yang ada. }\end{array}$ \\
\hline 2 & Memilih Soal Bermain & $\begin{array}{l}\text { Use Case memilih soal bermain merupakan proses memilih soal permainan } \\
\text { lalu menjawab pertanyaan pilihan berganda yang dijadikan sebagai test } \\
\text { belajar dan bermainnya pengguna. }\end{array}$ \\
\hline 3 & Mengelola Soal Permainan & $\begin{array}{l}\text { Use Case mengelola soal ini meruapakan proses mengelola soal yang } \\
\text { dilakukan oleh admin pada halaman administrator halaman soal }\end{array}$ \\
\hline
\end{tabular}

b. Skenario Use Case

Bagian ini merupakan skenario secara detail dari setiap use case yang telah didefinisikan ke dalam bentuk tabel skenario fungsi berikut ini.

Nama Use Case : Memilih materi belajar

Aktor : Pengguna

Tabel 4. Skenario Use Case Memilih Materi Belajar

\begin{tabular}{ll}
\hline \multicolumn{1}{c}{ Aksi Aktor } & \multicolumn{1}{c}{ Reaksi Sistem } \\
\hline 1.Memilih Materi mengenal huruf & Menampilkan halaman soal mengenal huruf \\
2. Memeilih materi mengenal angka & Menampilkan halaman soal mengenal angka \\
3. Memilih materi menyusun huruf & Menampilkan halaman soal menyusn hruf \\
\hline
\end{tabular}

Nama Use Case : Memilih soal bermain 
Aktor : Pengguna

Tabel 5. Skenario Use Case Memilih Soal Bermain

\begin{tabular}{|c|c|c|c|}
\hline \multicolumn{2}{|r|}{ Aksi Aktor } & \multicolumn{2}{|r|}{ Reaksi Sistem } \\
\hline 1. & Memilih Soal Permainan Susun Huruf & - & Menampilkan halaman Perminan soal susun huruf \\
\hline 2. & Memilih Permainan Mengenal huruf & - & $\begin{array}{l}\text { Menampilkan halaman Permainan soal mengenal } \\
\text { huruf }\end{array}$ \\
\hline 3. & Memilih Soal Permainan mengenal angka & - & Menampilkan halaman permainan soal mengenal angka \\
\hline
\end{tabular}

\subsection{Implementasi}

Dalam game eduaksi ini terdapat menu utama yaitu menu pemain dan admin. Pada menu pemain merupakan menu untuk membuka halaman menu pemain sedangkan menu admin untuk membuka haaman menu login admin untuk melakukan pengolahan soal-soal permainan. Adapun implementasi model belajar jigsaw yang disajikan pada media belajar game edukasi sebagai berikut.

a. Guru membuat 4 kelompok yang terdiri dari kumpulan peserta didik yang pintar dan pesera didik yang kurang pintar

b. Setiap kelompok berjumlah 2 orang yakni masing-masing terdiri dari murid pintar dan murid yang kurang pintar dalam 1 kelompoktersebut

c. Proses metode jigsaw dengan memanfaatkan teknologi komputerisasi yaitu menggunakan game edukasi sebagai media pembelajaran yang diterapkan untuk proses belajar.

d. Guru memaggil masing-masing ketua yang pintar dari masing-masing kelompok untuk memahami dan mendiskusikan bahan materi yang akan dibahas

e. Setelah itu guru mempersilahkan masing-masing ketua kelompok mengajarkan kepada anggota

f. Pada bagian ini dijelaskan hasil-hasil penelitian dan sekaligus diberikan pembahasan yang komprehensif. Hasil dapat disajikan dalam bentuk gambar, grafik, tabel dan lain-lain yang membuat pembaca mengerti dengan mudah. Pembahasan dapat dilakukan dalam beberapa sub-bab untuk lebih memperjelas uraian.

Adapun tampilan media pembelajaran dalam praktek jigsaw ini adalah sebagai gambar berikut:

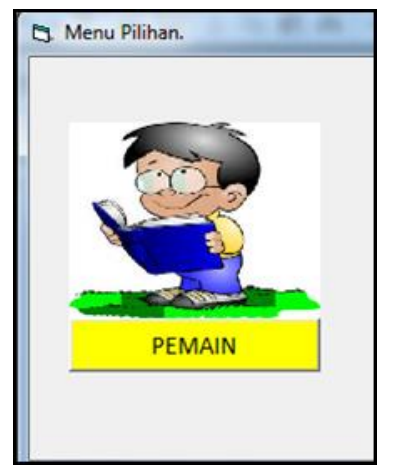

Gambar 3. Menu Utama Permainan

Gambar 3 diatas merupakan menu utama yang akan diakses oleh pemain. Menu admin hanya dapat diakses oleh admin yang di sini adalah wali kelas dengan melakukan login menggunakan username dan password agar dapat masuk ke dalam halaman pengolahan soal permainan. untuk Pada menu pemain yang diakses oleh user terdapat halaman menu yang berisikan menu pilihan dalam proses permainan. Agar lebih jelas penulis sajikan pada sub tampilan menu pemain sebagai berikut.

\subsubsection{Tampilan Halaman Bermain Pengenalan Huruf dan Angka}

Tampilan halaman bermain pengenalan huruf adalah tampilan permainan mengenal huruf abjad dari A sampai Z. pada permainan ini tampil huruf abjad dan dilengkapi menu dengarkan suara dan menu lanjut huruf selanjutnya serta menu mulai bermain dan menu kembali kemenu pemain. Adapun gambar dari halaman bermain pengenalan huruf adalah sebagai berikut. 


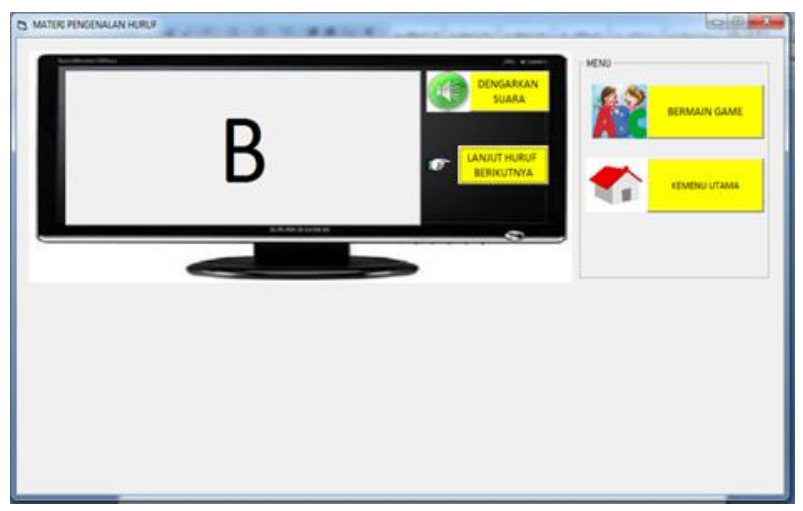

Gambar 4. Halaman Permainan Pengenalan Huruf

Pada gambar 4 di atas akan penulis jelaskan langkah-langkah cara bermainnya sebagai berikut.

a. Pemain mengklik tombol mulai bermain maka akan tampil soal huruf A seperti gambar di atas pada gambar 4.2

b. Pemain diberikan menu dengarkan suara huruf agar dapat memudahkan siswa-siswi dalam memahami bunyi dari huruf yang tampil pada soal. Dengan mengklik menu dengarkan suara huruf maka sistem akan memberikan output suara huruf.

c. Untuk melanjutkan huruf selanjutnya, user mengklik menu lanjut huruf berikutnya maka secara otomatis huruf akan berganti menjadi B dan seterusnya.

d. Menu kembali ke menu utama yang di-klik oleh user akan membawa user kembali ke halaman pemain.

\subsubsection{Tampilan Halaman Bermain Susun Huruf}

Tampilan halaman bermain susun huruf adalah tampilan permainan dengan aktivitas menyusun huruf. pada permainan ini tampil teks bacaan kalimat yang harus dijawab oleh user dengan menyusun huruf yang terdapat pada tombol-tombol abjad pada game edukasi juga bisa dengan menggunakan keyboard pada komputer. Pemain harus menjawab soal dengan mencocokkan soal teks kalimat dengan huruf yang disusun oleh pemain. Adapun gambar dari halaman bermain membaca kalimat adalah sebagai berikut:

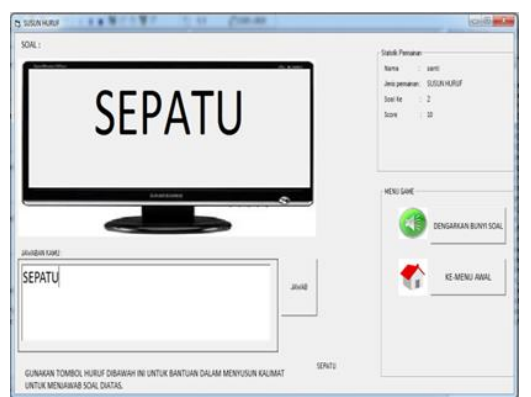

Gambar 5. Halaman Permainan Susun Huruf

Pada gambar 5 di atas akan penulis jelaskan langkah-langkah cara bermainnya sebagai berikut:

a. Pemain akan disajikan soal huruf pada teks kalimat dan memperhatikan dengan baik.

b. Pemain diberikan menu dengarkan suara huruf agar dapat memudahkan siswa-siswi dalam memahami bunyi ejaan huruf. Dengan mengklik menu dengarkan suara huruf maka sistem akan memberikan output suara huruf dari teks kalimat yang tampil.

c. Setelah user memahami bacaan dengan melihat bentuk tulisan dan mendengarkan suara huruf maka user dapat memilih jawaban dari pertanyaan yang diberikan. Pada pilihan jawaban ada 4 (empat) pilihan. User harus mengklik salah satunya untuk dicocokkan dengan soal dan jawaban.

d. Setelah itu akan tampil konfirmasi jawaban apakah pemain yakin dengan jawaban yang dipilih atau tidak. jika user mengklik ya maka sistem akan merespon jawaban tersebut apakah benar atau salah dan jika user mengklik tidak maka jawaban tidak akan diproses oleh sistem.

e. Saat jawaban benar maka akan terdengar suara yes dan sistem akan menampilkan soal berikutnya. Jika jawaban salah akan terdengar suara salah maka soal tidak akan lanjut melainkan tetap pada soal pertama.

f. Menu dengarkan suara berfungsi untuk mendengarkan suara bunyi bacaan pada soal kalimat. Menu

g. Ke menu awal berfungsi untuk menampilkan halaman pemain. 


\subsection{Pengujian Sistem}

Pada penelitian ini digunakan metode pengujian black box testing. Pengujian dilakukan dengan menguji bagian antarmuka dari sistem informasi, setiap bagian dari antarmuka tersebut diuji agar dapat ditentukan apakah sistem sudah berjalan sesuai dengan fungsi yang diharapkan. Tujuan dari pengujian ini adalah untuk mengetahui kesalahan pada sistem yang dibuat. Berikut adalah hasil pengujian menggunakan metode black box testing yang ditampilkan dalam bentuk tabel:

Tabel 4. Hasil Pengujian Sistem

\begin{tabular}{llll}
\hline No & Kelas $\boldsymbol{U j i}$ & Skenario Pengujian & Hasil \\
\hline & Memilih Materi Belajar & $\begin{array}{l}\text { memilih materi belajar merupakan proses memilih materi } \\
\text { pembelajaran, melihat isi materi dan mendengarkan suara pengucapan } \\
\text { penjelasan dari setiap materi yang ada. }\end{array}$ \\
\hline \multirow{2}{*}{ Memilih Soal Bermain } & $\begin{array}{l}\text { memilih soal bermain merupakan proses memilih soal permainan lalu } \\
\text { menjawab pertanyaan pilihan berganda yang dijadikan sebagai test Sesuai } \\
\text { belajar dan bermainnya pengguna. }\end{array}$ \\
\hline
\end{tabular}

\section{KESIMPULAN}

Berdasarkan penelitian dan pembahasan yang dilakukan, maka dapat disimpulkan beberapa hal sebagai berikut:

a. Game edukasi yang dibuat memiliki pengaruh yang positif dalam proses pembelajaran karena media game edukasi dilengkapi dengan gambar, tulisan serta audio visual yang membantu anak didik lebih memahami pelajaran yang disampaikan.

b. Bahwasannya anak penderita tunawicara ini dapat lebih memahami pelajaran yang disampaikan dengan cara belajar kooperatif sehingga dapat menyerap pelajaran dengan baik.

c. Dalam mengajari dan menyampaikan pelajaran pada anak tunawicara harus dengan kesabaran dari orangtua maupun tenaga pendidik dengan mengajarkan pelajaran secara berulang agar apa yang disampaikan oleh guru atau orangtua dapat diserap dengan baik oleh anak didik.

\section{REFERENSI}

[1] F. Edi, P. T. Informatika, and F. U. A. Labuhanbatu, "UNET | Jurnal Ilmiah Teknik Informatika LPPM Universitas Al Washliyah Labuhanbatu UNET | Jurnal Ilmiah Teknik Informatika ISSN . 2460-3694, Vol . 2 No . 1 Februari 2018,” vol. 2, no. 1, pp. 2-5, 2018.

[2] D. I. G. H. Wirhan Fahrozi, Samsir, "Penerapan E-Commerce Pada Toko Bunga Underwear," J. Tek. Inform., vol. 04, no. 01, pp. 1-6, 2020.

[3] W. Fahrozi, P. T. Informatika, T. Informatika, F. U. A. Labuhanbatu, T. Mulia, and K. Medan, "UNET : Jurnal Teknik Informatika LPPM - Universitas Al Washliyah Labuhanbatu 23 |P a g e UNET : Jurnal Teknik Informatika Sebagai langkah awal yang dilakukan supaya dapat mengetahui gambaran permasalahan yang dihadapi dalam menentukan rasa yam serama a," vol. 3, no. 5, pp. 2327, 2019.

[4] Samsir, "Klasifikasi Penyakit Tenggorokan Hidung Telinga ( THT ) Menggunakan Jaringan Syaraf Tiruan Dengan Metode Learning Vektor Quantization ( THT ) Di RSUD Rantauprapat Labuhanbatu Klasifikasi penyakit Tenggorokan Hidung Telinga ( THT ) Menggunakan,” vol. 05, no. 01, pp. 3847, 2019.

[5] D. Indra et al., "SPK Untuk Pemilihan Kepala Sekolah Menggunakan Metode Saw dan Profile Matching," vol. 4, no. 1, pp. 7-12, 2020.

[6] M. Siddik and S. Samsir, "Rancang Bangun Sistem Informasi Pos (Point of Sale) Untuk Kasir Menggunakan Konsep Bahasa Pemrograman Orientasi Objek,” JOISIE (Journal Inf. Syst.

Informatics Eng., vol. 4, no. 1, p. 43, 2020, doi: 10.35145/joisie.v4i1.607.

[7] Samsir and Syaiful Zuhri Harahap, "Application Design Resume Medical By Using Microsoft Visual Basic. Net 2010 At the Health Center Appointments,” Int. J. Sci. Technol. Manag., vol. 1, no. 1, pp. 14-20, 2020, doi: 10.46729/ijstm.v1i1.5.

[8] P. T. Informatika and F. U. A. Labuhanbatu, "U-NET : Jurnal Teknik Informatika LPPM Universitas Al Washliyah Labuhanbatu 18 |P a g e U-NET : Jurnal Teknik Informatika Sebagai langkah awal yang dilakukan supaya dapat mengetahui gambaran permasalahan yang dihadapi oleh bagian kesiswaan adalah denga," vol. 3, no. 4, pp. 18-22, 2019.

[9] M. V. B. Net, "PADA TOKO URIP MOTOR,” no. September, pp. 1-6, 2020.

[10] J. H. P. Sitorus et al., "Perancangan pengontrol lampu rumah miniatur dengan menggunakan micro controler arduino berbasis android 1," vol. 4, no. 1, pp. 1-11, 2020.

[11] U. Verawardina, F. Edi, and R. Watrianthos, “Analisis Sentimen Pembelajaran Daring Pada Twitter di Masa Pandemi COVID-19 Menggunakan Metode Naïve Bayes,” vol. 5, pp. 157-163, 2021, doi: 
10.30865/mib.v5i1.2604.

[12] S. Zulkifli, "Implementasi Sistem Keamanan SQL Injection Dalam berbasis web," Ejurnal.Univalabuhanbatu.Ac.Id, vol. 04, no. 01, pp. 13-17, 2020, [Online]. Available: https://ejurnal.univalabuhanbatu.ac.id/index.php/u-net/article/download/164/130. 